\title{
Multimodality as a Communicative Tool for Social Engagement and Reform
}

\author{
Brennan Thomas, Ph.D. \\ Faculty of Literature \& Languages, Saint Francis University, Pennsylvania \\ (D)/0000-0002-6599-1007
}

DOI: https://dx.doi.org/10.46679/978819484836304

\begin{abstract}
This article acknowledges the viability of multimodal projects in first-year college-level writing courses in accordance with the evolution of composition pedagogy over the past forty years. Since the 1982 publication of Hairston's article "The Winds of Change" forecasting the end of the then-ubiquitous current-traditional approach, composition pedagogy has undergone paradigm shifts from process to post-process theory and from textual to digital modes of composition. Inspired by Goodwin's (2020) research on students' multimodal responses to local community issues, I developed a public media project for my first-year writing course for which students created media texts addressing local, regional, national, and global issues of their choosing. The project synthesizes the public and interpretative dimensions of writing identified by post-process scholars with elements of multimodality and civic engagement to help students understand how public media texts raise social awareness of current issues and mobilize community efforts toward unified resolution of such issues.
\end{abstract}

Keywords: post-process movement, digital composition, public media, social awareness, social justice

Multimodality as a Communicative Tool for Social Engagement and Reform 
Hairston correctly predicted in her seminal 1982 article "The Winds of Change" that pedagogical approaches to writing instruction would undergo a major sea change-that the current traditional paradigm that had dominated writing instruction for much of the twentieth century was about to be replaced (p. 77). The process movement had been gaining strength during the previous decade, with anchoring research by Emig (1971), Murray (1971), Perl (1979), and Sommers (1980) building a case to replace the product-oriented current-traditional paradigm as writing's primary pedagogical approach. By the mid-1980s, writing instructors had shifted their focus from the finished product to the steps to achieve that product, giving particular emphasis to the prewriting and rewriting stages of composing (Flower \& Hayes, 1981, p. 366) and providing students various methods for moving through each stage while conceptualizing writing as a recursive, non-linear process (Kent, 1999, p. 1).

\section{Post-Process: Writing is/as Social Interaction}

Nearly forty years later, these key elements of the process movement still define much of the work we do with our students. We still encourage students to explore their ideas through prewriting, to engage simultaneously in exploring, drafting, and revising as their ideas take shape, and to refine their ideas according to their and their readers' expectations. Even as we entered the post-process movement in the late 1990s, these elements of the process movement remained a core part of our pedagogy (Kent, 1999, p. 1), providing a sense of structure and direction for students as they composed in various modes of writing.

But, as many composition theorists acknowledged, these elements alone were insufficient for guiding students to understand more fully how their writing's meaning is socially influenced or interpreted by audiences. Moreover, the three basic components of the process movement's conceptualization of writing-prewriting, writing 


\section{This is a limited preview of the chapter.}

To read the full-text chapter, get access by purchasing this chapter or consider buying the complete book. If your library has subscription to EBSCOhost, the chapter including other chapters of the book can be accessed through your library.

This chapter is a part of the book, 'Development of Innovative Pedagogical Practices for a Modern Learning Experience' ISBN (paperback): 978-81948483-6-3; ISBN (ebook): 978-81-948483-7-0

Book DOI: https://dx.doi.org/10.46679/9788194848363

Available via CSMFL Bookstore, Amazon, Google Play Books, EBSCOhost \& EBSCO eBooks 
selection process. I will also encourage students to explore the benefits and drawbacks of converting their documents, if in print form, to digital media, and vice versa. Students who created print-based documents reported in their reflections struggling with limited space for text and imagery. Those who created digital media were concerned about sustaining viewers' interests and vying for their attention amidst thousands of other online texts. Additional opportunities to explore the limitations of these media would likely enhance students' understanding of how their chosen media formats and elements affect their and their audiences' abilities and willingness to engage in meaningful communicative exchanges. Ultimately, however, I am pleased with students' responses to this multimodal unit. Their projects demonstrated creativity and adherence to (and in some cases clever deviation from) media conventions, as well as recognition of how audiences' knowledge of and attitudes towards students' selected issues can be effectively shaped or changed.

\section{References}

Arola, K. L., Sheppard, J., \& Ball, C. E. (2014). Writer/designer: A guide to making multimodal projects. Bedford/St. Martin's.

Calderón, G.(2014, November 5). Social change needs engaged communities, not heroes [Video]. YouTube.

https://www.youtube.com/watch?v=WdHBWL4LK88

Covino, W. A., \& Jolliffe, D. A. (1995). Rhetoric: Concepts, definitions, boundaries. Allyn and Bacon.

Emig, J. (1971). The composing processes of twelfth graders. National Council of Teachers of English.

Flower, L., \& Hayes, J. R. (1981). A cognitive process theory of writing. College Composition and Communication, 32(4), 365-387.

George, D. (2002). From analysis to design: Visual communication in the teaching of writing. College Composition and Communication, 54(1), 11-39. 
Goodwin, P. (2020). Embodied subjectivities and the city: Intervening in local public debates through multimodality. College Composition and Communication, 72(2), 224-250.

Hairston, M. (1982). The winds of change: Thomas Kuhn and the revolution in the teaching of writing. College Composition and Communication, 33(1), 76-88.

Kent, T. (Ed.). (1999). Post-process theory: Beyond the writing-process paradigm. Southern Illinois University Press.

Kinneavy, J. E. (1969). The basic aims of discourse. College Composition and Communication, 20(5), 297-304.

Murray, D. (1971). Teach writing as a process, not product. The Leaflet, 71(3), 11-14.

Ong, W. J. (1975). The writer's audience is always a fiction. PMLA, 90(1), 9-21.

Perl, S. (1979). The composing processes of unskilled college writers. Research in the Teaching of English, 13(4), 317-336.

Romano, T. (2000). Blending genre, altering style: Writing multigenre papers. Boynton/Cook.

Sommers, N. (1980). Revision strategies of student writers and experienced adult writers. College Composition and Communication, 31(4), 378-388.

\section{About the author}

Dr. Brennan Thomas is an associate professor of English at Saint Francis University (Loretto, Pennsylvania), where she directs the university's writing center and teaches courses in composition, pedagogy, and novel writing, as well as a first-year seminar, titled "Disney Memes and Themes," on the animated films of Disney and Pixar Studios. Her research interests include writing center administration and popular media studies. 
